\title{
CONTRIBUIÇÃO METODOLÓGICA À ESTIMATIVA DO PERIGO DE CONTAMINAÇÃO DAS ÁGUAS SUBTERRÂNEAS
}

\section{METHODOLOGICAL CONTRIBUTION TO EVALUATE THE CONTAMINATION HAZARD OF GROUNDWATER}

\section{Richard Fonseca FRANCISCO ${ }^{1}$, Antonio Celso de Oliveira BRAGA ${ }^{1}$, José Luiz ALBUQUERQUE FILHO ${ }^{2}$}

${ }^{1}$ Universidade Estadual Paulista - UNESP. Departamento de Geologia, Instituto de Geociências e Ciências Exatas. Avenida 24-A, 1.515, Bela Vista, Rio Claro - SP. E-mails: richard.fonseca@unesp.br; oliveira.braga@unesp.br

${ }^{2}$ Instituto de Pesquisas Tecnológicas do Estado de São Paulo (IPT), Centro de Tecnologias Geoambientais, Laboratório de Recursos Hídricos e Avaliação Geoambiental. Av. Prof. Almeida Prado, 532 - Butantã, São Paulo - SP. E-mail: albuzelu@ipt.br

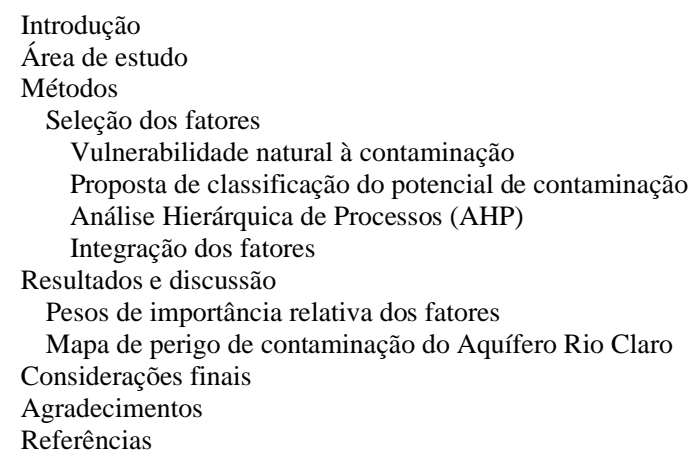

RESUMO - Em função do crescente número de áreas contaminadas, que comprometem a qualidade dos aquíferos e constituem riscos à saúde humana, torna-se imprescindível o estabelecimento de instrumentos para o planejamento e gestão do uso do solo, visando à proteção das águas subterrâneas contra a poluição. Por esse motivo, o objetivo deste trabalho foi desenvolver e aplicar, experimentalmente, uma proposta metodológica para estimar o perigo de contaminação das águas subterrâneas. Portanto, foram selecionados, ponderados e integrados os fatores vulnerabilidade natural à contaminação e o uso e cobertura do solo, com suporte da Avaliação Multicritério (AMC) e técnicas de geoprocessamento operadas em ambiente SIG. A área teste escolhida para aplicar este novo modelo foi o aquífero Rio Claro, situado no município de Rio Claro/SP. Como resultado, 72\% da área de estudo foi classificada com alto perigo de contaminação, onde predominam atividades com potencial de contaminação significativo, como a área urbanoindustrial e cultivos de cana-de-açúcar e de cítricos, que juntos representam $65 \%$ da superfície total. Devido à robustez do produto gerado, simplicidade conceitual e à praticidade na utilização, o sistema de avaliação proposto poderá desempenhar um papel importante na definição de áreas prioritárias para a proteção das águas subterrâneas.

Palavras-chave: Aquífero Rio Claro. Perigo. Suporte à decisão. AHP. Geoprocessamento.

ABSTRACT - Due to increase in the number of contaminated areas, which compromise the groundwater quality and constitute risks to human health, it is essential to establish instruments for land use planning and management, aiming at the groundwater protection against pollution. For this reason, the aim of this work was to develop and apply, experimentally, a methodological proposal to assess the contamination hazard of groundwater. Therefore, natural vulnerability to contamination and land use and cover factors were selected, weighted and integrated, with support of Multicriteria Evaluation (MCE) and geoprocessing techniques operated in GIS environment. Located in the Rio Claro municipality, São Paulo State, Brazil, the Rio Claro aquifer was chosen to apply this new evaluation model. As result, $72 \%$ of the study area was classified as high contamination hazard, where activities with significant contamination potential predominate, such as industrial urban areas and sugar cane and citrus crops, which together represent $65 \%$ of total surface. Due to robust result, conceptual simplicity and practical use, the proposed evaluation system may perform an important role in defining priority areas for groundwater protection.

Keywords: Rio Claro Aquifer. Hazard. Decision Support. AHP. Geoprocessing.

\section{INTRODUÇÃO}

Em função do crescente número de áreas contaminadas, que comprometem a qualidade das águas subterrâneas e constituem riscos à saúde humana, torna-se imprescindível o estabelecimento de instrumentos para o planejamento e gestão do uso do solo, visando à proteção dos aquíferos contra a poluição.

Portanto, trabalhos com enfoque na estimativa da vulnerabilidade natural e perigo de conta- minação das águas subterrâneas devem ser conduzidos, na medida em que permitem estimar áreas mais sensíveis à poluição, além de viabilizarem a identificação e a sistematização de fontes com maior potencial de contaminação. Desse modo, é possível planejar melhor a instalação e a operação de empreendimentos potencialmente nocivos aos aquíferos, destacando regiões prioritárias para o delineamento e 
implementação de um conjunto de medidas protetivas para as águas subterrâneas (Braga et al., 2018).

Conceitualmente, o termo "vulnerabilidade natural" é definido como sendo a suscetibilidade de um aquífero ser afetado por uma carga contaminante aplicada na superfície do terreno, sendo determinada pelas características intrínsecas dos estratos acima da zona saturada (Foster \& Hirata, 1988). Atualmente, o termo "perigo de contaminação" tem o mesmo significado de "risco de contaminação", que expressa o resultado da interação entre a carga poluente antrópica e a vulnerabilidade natural à contaminação do aquífero (Foster et al., 2006).

Devido à relevância do tema, nos últimos anos diversas pesquisas têm sido desenvolvidas para avaliar o perigo de contaminação das águas subterrâneas, podendo ser citados os trabalhos de Foster et al. (2006), Albuquerque Filho et al. (2011), Iritani et al. (2013), Meira et al. (2014), Kazakis \& Voudouris (2015), Entezari et al. (2016), Sullivan \& Gao (2017), Jenifer \& Jha (2018), Kumar \& Krishna (2019) e Çil et al. (2020).

Grande parte destas pesquisas concentraram seus esforços na proposição de esquemas de classificação do potencial de contaminação de fontes pontuais e difusas, estabelecendo conceitos e pressuposições básicas que devem ser adaptadas à área sob análise, aos objetivos do trabalho e às situações que o modelo de avaliação adotado se propõe a compreender.

Contudo, ainda não há um consenso sobre a importância relativa entre os fatores vulnerabilidade natural e fontes de contaminação, cuja interação varia em função das características geológicas e hidrogeológicas da área, inclusive das propriedades físico-químicas do contaminante ou grupo de contaminantes. Ademais, a definição das classes de perigo deriva sempre do julgamento subjetivo e empírico de especialistas, podendo ocasionar certo grau de imprecisão, interpretações distorcidas da realidade e falhas na apropriação dos resultados.

Nesse sentido, a estruturação da estimativa do perigo no contexto da Avaliação Multicritério (AMC) pode tornar o processo decisório menos subjetivo e mais preciso, conduzindo a um método de estimativa com maior robustez, a fim de obter resultados mais consistentes.

Perante o exposto, o objetivo deste trabalho foi desenvolver e aplicar, experimentalmente, uma proposta metodológica para estimar o perigo de contaminação das águas subterrâneas. Portanto, foram selecionados, ponderados e integrados os fatores vulnerabilidade natural à contaminação e o uso e cobertura do solo, com suporte da Avaliação Multicritério (AMC) e técnicas de geoprocessamento operadas em ambiente SIG.

\section{ÁREA DE ESTUDO}

A área de estudo representa um fragmento da Formação Rio Claro, com superfície total de aproximadamente $95 \mathrm{~km}^{2}$. Localiza-se no município de Rio Claro, no centro-leste do Estado de São Paulo, entre as coordenadas UTM 232692 - 243646 W e 7512521 - 7535805 S (Figura 1).

Quanto ao contexto geológico (Figura 2), a área de estudo situa-se na porção nordeste da Bacia Sedimentar do Paraná, onde ocorrem rochas sedimentares e vulcânicas das eras: Paleozoica (Subgrupo Itararé, formações Tatuí, Irati e Corumbataí), Mesozoica (Formação Pirambóia e Intrusivas Básicas) e Cenozoica (Formação Rio Claro e Coberturas Indiferenciadas) (IG, 1986).

A Formação Rio Claro apresenta como características marcantes: fraca litificação e profunda alteração pedogenética, espesso solo arenoso e domínio de litotipos arenosos, esbranquiçados, amarelados a avermelhados, variando de areia fina a grossa, com intercalação de camadas de conglomerados e de sedimentos argilosos. A espessura máxima é da ordem de 40 metros, predominando valores entre 25 metros e 30 metros (Zaine, 1994).

No que se refere às relações de contato, a Formação Rio Claro assenta-se em discordância sobre os argilitos e siltitos da Formação Corumbataí, no município de Rio Claro/SP (Melo, 1995).

O Aquífero Rio Claro é uma unidade hidrogeológica constituída por sedimentos pouco comsolidados da Formação Rio Claro, apresentando extensão local, superfície descontínua e livre, cuja recarga ocorre por toda a sua extensão, diretamente através da infiltração das precipitações. A rede hidrográfica local atua como zonas de descarga do aquífero Rio Claro, as quais, geralmente, situam-se próximas ao contato do aquífero com o aquitardo subjacente, constituído pela Formação Corumbataí (DAEE, 1981; Oliva, 2006).

Chang et al. (2005) determinaram valores de 
condutividade hidráulica para a zona saturada situados entre $10^{-2} \mathrm{~cm} / \mathrm{s}$ e $10^{-4} \mathrm{~cm} / \mathrm{s}$, atribuindo à Formação Rio Claro excelente permo-porosidade.
Para o aquífero Rio Claro, a razão anual entre a recarga e a precipitação foi estimada em 13\% (Chang \& Nogueira, 2015).

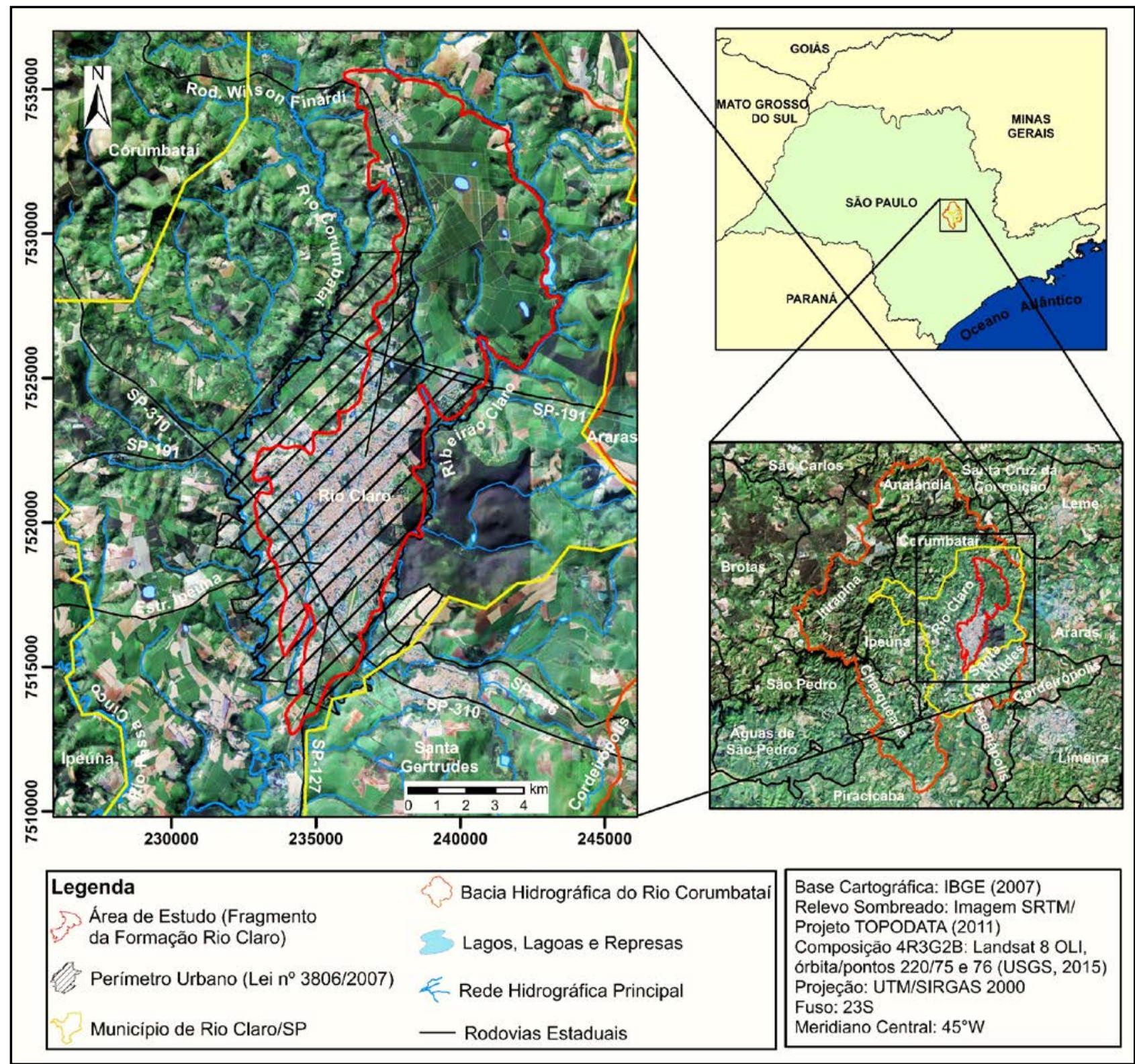

Figura 1 - Mapa de localização da área de estudo.

\section{MÉTODOS}

\section{Seleção dos fatores}

Para avaliar o perigo de contaminação, foram selecionados os seguintes fatores: uso e cobertura do solo (SMA \& IG, 2016), que representa fontes de contaminação difusas; e a vulnerabilidade natural, a qual foi estimada através do método SDR (Francisco et al., 2019).

É oportuno destacar que as fontes difusas de contaminação não produzem plumas de contaminação bem definidas, mas normalmente afetam uma área e, portanto, um volume muito maior do aquífero. Em contrapartida, as fontes pontuais, de um modo geral, produzem plumas bem definidas e mais concentradas, o que facilita sua identificação e, em alguns casos, o seu controle.

Por outro lado, quando as atividades poluentes de origem pontual são pequenas e múltiplas, acabam representando, ao final, uma fonte basicamente difusa no que diz respeito à identificação e ao controle (Foster et al., 2006).

Por isso, preferiu-se a abordagem por fontes de contaminação difusas, visto que oferece uma análise mais ampla do perigo, resultando em produtos temáticos em escala regional, com aplicabilidade por gestores públicos em âmbito municipal, que é exatamente o que se pretende com este trabalho. 


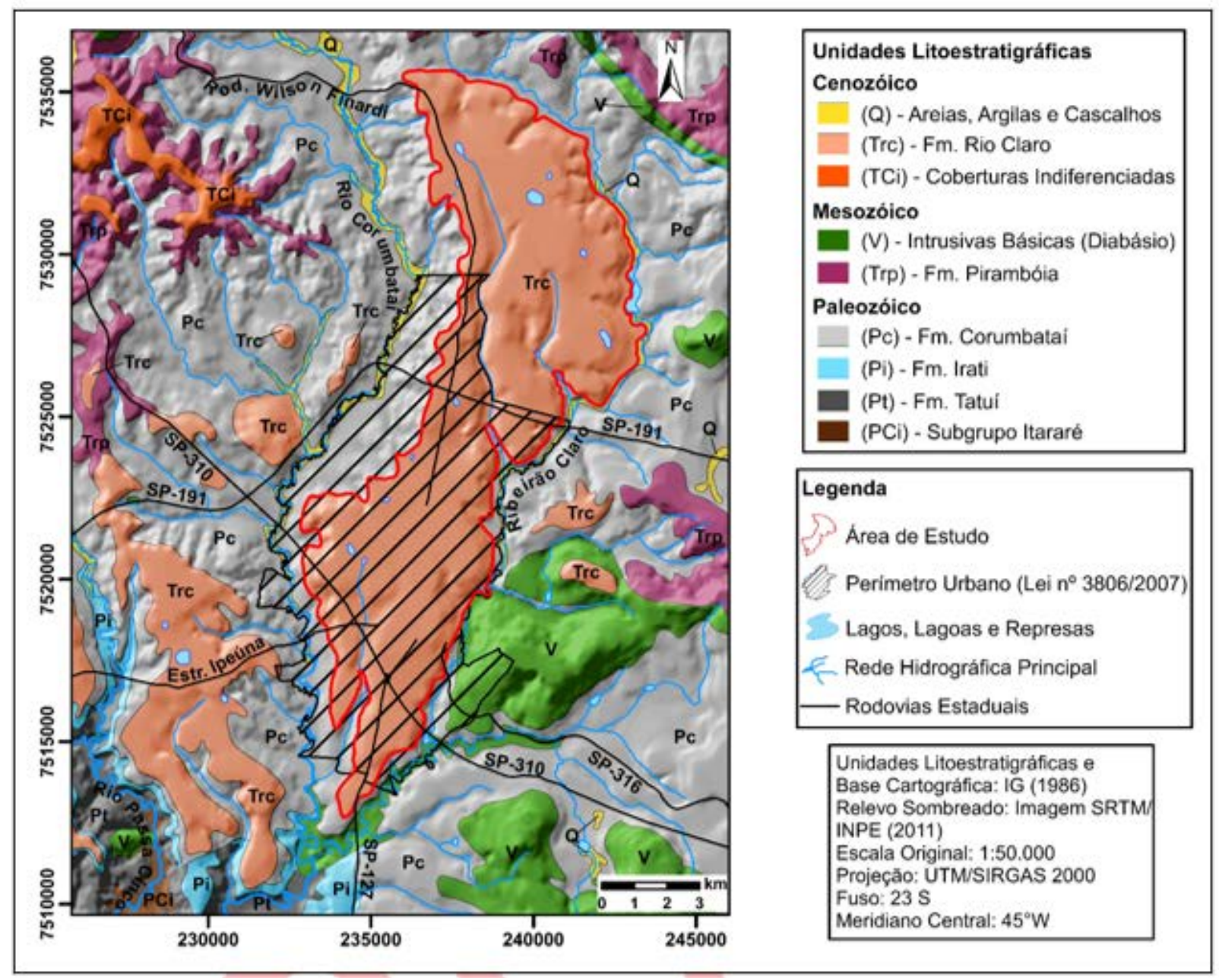

Figura 2 - Contexto geológico da área de estudo (Fonte: Adaptado de IG, 1986).

\section{Vulnerabilidade natural à contaminação}

O método SDR é um sistema paramétrico de avaliação da vulnerabilidade natural de aquíferos livres granulares, perfeitamente aplicável ao aquífero Rio Claro. Trata-se de um método de fácil implementação e simplicidade conceitual, o qual estima a vulnerabilidade através de apenas três fatores, algo muito interessante considerando o cenário de escassez de dados em muitas regiões no Brasil.

O primeiro fator é a condutância longitudinal unitária $\left(\mathrm{S}_{\mathrm{i}}\right)$, que expressa a razão entre as espessuras e resistividades elétricas das camadas sobrejacentes ao aquífero de interesse, indicando indiretamente as características geológicas e hidrogeológicas dos estratos de cobertura. A partir do cálculo da condutância longitudinal total (S) da zona não saturada, tem-se que, quanto maior o valor de $S$, maior será o grau de proteção do aquífero, pois: (1) quanto maior a espessura da zona insaturada, maior o tempo de percolação do contaminante (maior filtro); e (2) quanto menor sua resistividade, mais argiloso e menos permeável é o material (Braga, 2016).
O segundo e o terceiro fator são a declividade do terreno (D) e a taxa de recarga do aquífero (R), ambos relacionados à quantidade de águas pluviais que efetivamente infiltram no solo e atingem o aquífero, podendo transportar consigo os poluentes.

No método SDR, os índices de vulnerabilidade natural são obtidos por meio da Equação 1 , a seguir apresentada.

$$
\mathrm{V}_{\mathrm{SDR}}=0,54 . \mathrm{S}+0,14 . \mathrm{D}+0,32 . \mathrm{R}
$$

Onde: $\mathrm{V}_{\mathrm{SDR}}=$ mapa de vulnerabilidade natural do método SDR; $\mathrm{S}$ = mapa normalizado do fator condutância longitudinal total da zona insaturada; $\mathrm{D}=$ mapa normalizado do fator declividade; $\mathrm{R}$ = mapa normalizado do fator recarga.

De modo geral, todo o aquífero Rio Claro foi classificado como de vulnerabilidade alta, a partir da aplicação experimental do método SDR por Francisco et al. (2019), cujo resultado é compatível com aqueles reportados em trabalhos anteriores que empregaram métodos tradicionais, como o GOD e o DRASTIC. 
A alta vulnerabilidade ocorre, essencialmente, devido às características da Formação Rio Claro, onde predominam pequenas profundidades do N.A., materiais arenosos e muito permeáveis, inclusive fatores climáticos e topográficos favoráveis à recarga do aquífero e transporte de poluentes em direção a ele.

\section{Proposta de classificação do potencial de contaminação}

O mapa de uso e cobertura do solo foi estruturado em 3 níveis hierárquicos de abstração, configurando um sistema aberto e multinível, que possibilita a inserção de níveis cada vez mais detalhados de informação (SMA \& IG, 2016).

O nível I comporta o maior grau de generalização da informação, sendo destacados na tabela de atributos os tipos de cobertura do solo da UGRHI 05 - PCJ. O nível II constitui uma subdivisão, incluindo um detalhamento quanto à função ou atividade a que se destina cada classe de cobertura do solo identificada no nível I.

Assim, cada classe de uso definida no nível II integra uma noção de funcionalidade dos objetos que a compõe. O nível III inclui uma subdivisão das classes de uso do solo, apontadas no nível II, em classes de atributos.

A classificação do potencial de contaminação do uso do solo foi baseada nos métodos POSH (Foster et al., 2006) e IS (Ribeiro et al., 2001), inclusive nos trabalhos da Empresa Brasileira de Pesquisa Agropecuária - EMBRAPA (Gomes, 2008), do Instituto de Pesquisas Tecnológicas do Estado de São Paulo - IPT (Albuquerque Filho et al., 2011), do Instituto Geológico do Estado de São Paulo - IG (Iritani et al., 2013) e da Comissão Europeia de Cooperação em Ciência e Tecnologia (COST 620, 2003).

A partir da compilação e interpretação destes trabalhos, foi proposto um sistema de classificação do uso do solo quanto ao potencial de contaminação, com aplicabilidade a qualquer área de estudo. No caso da Formação Rio Claro, o sistema de indexação da figura 3 foi aplicado ao nível II de abstração (Figura 4). Devido à diversidade e complexidade das atividades inerentes à classe de uso "Grande Equipamento", preferiu-se utilizar o nível III para a indexação das fontes contidas nesta classe.

Desse modo, foram atribuídos valores numéricos aos tipos de uso do solo, com variação entre 0 e 1, em função do potencial gerador de cargas poluidoras pelas atividades exercidas.

Posteriormente, foi gerado um mapa de uso e cobertura do solo contendo a classificação proposta, a fim de integrá-lo ao mapa de vulnerabilidade natural.

\section{Análise Hierárquica de Processos (AHP)}

No contexto da Avaliação Multicritério (AMC), foi empregada a Análise Hierárquica de Processos (AHP) para definir os pesos de importância relativa dos fatores considerados no método de avaliação proposto.

Desenvolvida por Saaty (1980), a AHP propõe a construção de uma matriz de comparação pareada entre os fatores, com base numa escala contínua de nove pontos (Tabela 1). A matriz gerada é simétrica e, portanto, somente a metade triangular superior necessita ser preenchida. As células remanescentes são recíprocas daquelas já preenchidas.

A consistência dos julgamentos paritários é avaliada por sua Razão de Consistência (RC), que representa a probabilidade de que os valores da matriz tenham sido gerados ao acaso ou randomicamente. Segundo Saaty (1980), os valores de RC devem estar sempre abaixo de 0,10 , caso contrário, as comparações paritárias devem ser reanalisadas.

Para que fosse obtido apenas um conjunto de pesos de fator que sintetizasse a decisão do grupo de especialistas, foi utilizada a Agregação de Prioridades Individuais (API) (Forman \& Peniwati, 1998). Na API, cada indivíduo efetua seus julgamentos separadamente. Em seguida, calcula-se a média geométrica entre os pesos de fator gerados individualmente na AHP, obtendo-se, assim, os pesos finais que refletem a avaliação integrada do grupo.

\section{Integração dos fatores}

Para gerar o mapa de perigo de contaminação, os fatores foram agregados por meio da Combinação Linear Ponderada (CLP) (Voogd, 1983). A partir da CLP, cada fator normalizado é multiplicado pelo seu respectivo peso e, em seguida, são somados conforme a Equação 2:

$$
\mathrm{P}=\sum \mathrm{w}_{\mathrm{i}} \cdot \mathrm{x}_{\mathrm{i}}
$$

onde: $\mathrm{P}=$ perigo de contaminação; $\mathrm{w}_{\mathrm{i}}=$ peso do fator $\mathrm{i} ; \mathrm{x}_{\mathrm{i}}=$ escore do fator $\mathrm{i}$. Na figura 5 , esquematiza-se o processo decisório do método proposto, considerando o contexto da Avaliação Multicritério (AMC). 


\begin{tabular}{|c|c|c|}
\hline \multicolumn{3}{|r|}{ SUPERFÍCIES ARTIFICIAIS } \\
\hline Uso e Cobertura & Índice & \begin{tabular}{|l} 
Justificativas \\
\end{tabular} \\
\hline $\begin{array}{l}\text { Áreas de Disposição Irregular de } \\
\text { Resíduos (Urbanos, Industriais e } \\
\text { Serviços de Saúde) e Áreas de } \\
\text { Descarga de Efluentes Sem } \\
\text { Tratamento }\end{array}$ & 1,00 & $\begin{array}{l}\text { Em 2018, cerca de } 41 \% \text { do total de Resíduos Sólidos Urbanos (RSU) gerados no Brasil } \\
\text { foram dispostos em locais inadequados. Ou seja, } 29,5 \text { milhões de toneladas de RSU } \\
\text { ainda são despejados em lixões ou aterros controlados (ABRELPE, 2019). Somado a } \\
\text { isto, os resíduos e efluentes depositados nessas áreas geralmente apresentam elevada } \\
\text { toxicidade, patogenicidade, são bastante móveis e, por vezes, persistentes no meio } \\
\text { hidrogeológico, constituindo fontes com elevado potencial de contaminação. }\end{array}$ \\
\hline Áreas de Extração Mineral & 0,80 & $\begin{array}{l}\text { Além de remover horizontes de solo que conferem proteção ao aquífero, a extração } \\
\text { mineral produz rejeitos, os quais em contato com a água da chuva, pode resultar em } \\
\text { poluentes que podem ser lixiviados e se infiltrarem nas águas subterrâneas. }\end{array}$ \\
\hline $\begin{array}{l}\text { Áreas Industriais e Equipamentos } \\
\text { Gerais (Aterros Sanitários, ETE, } \\
\text { ETA, entre outros) }\end{array}$ & 0,80 & $\begin{array}{l}\text { Para a indexação desta classe de uso do solo, devem ser considerados a diversidade de } \\
\text { atividades desenvolvidas e os efluentes e resíduos gerados, que se não forem tratados } \\
\text { e dispostos adequadamente, podem causar impactos ambientais adversos. }\end{array}$ \\
\hline $\begin{array}{l}\text { Áreas Urbanas (Edificações do } \\
\text { Tecido Urbano Contínuo e } \\
\text { Descontínuo) }\end{array}$ & 0,73 & $\begin{array}{l}\text { Trata-se de tecido urbano muito diversificado, em termos de atividades potencialmente } \\
\text { poluidoras (Ex.: postos de combustíveis, ferros-velhos, lava-rápidos e oficinas } \\
\text { mecânicas), padrão das edificações, densidade/estágio da ocupação e ordenamento } \\
\text { urbano. Portanto, estas áreas apresentam diferentes níveis quanto à intensidade/tipo de } \\
\text { coleta, armazenamento, tratamento e disposição de resíduos sólidos e esgotos } \\
\text { domésticos, considerando também a dependência, em alguns locais, de saneamento in } \\
\text { situ (latrinas e fossas sépticas). Portanto, utilizou-se a média aritmética dos valores } \\
\text { propostos por Ribeiro et al. (2001), para áreas urbanizadas contínuas }(0,75) \text { e } \\
\text { descontínuas }(0,70) \text {. }\end{array}$ \\
\hline Cemitérios & 0,70 & $\begin{array}{l}\text { Atualmente, a preocupação com os cemitérios é crescente, pois a maioria destes locais } \\
\text { são antigos e não apresentam impermeabilização do solo e sistemas de coleta e } \\
\text { destinação do necrochorume. A respeito disto, a Resolução SMA n }{ }^{\circ} 10 / 17 \text { definiu os } \\
\text { serviços de sepultamento como sendo uma atividade potencialmente geradora de áreas } \\
\text { contaminadas (São Paulo, 2017). }\end{array}$ \\
\hline $\begin{array}{l}\text { Aeroportos, Zonas Portuárias, } \\
\text { Infraestruturas de Rede Rodoviária } \\
\text { e Ferroviária }\end{array}$ & 0,70 & $\begin{array}{l}\text { Suas atividades envolvem o manuseio de óleos e graxas, inclusive a utilização de } \\
\text { combustíveis. Além disso, podem ocorrer o armazenamento temporário e o transporte } \\
\text { de produtos químicos altamente tóxicos, inflamáveis e corrosivos. Na ocasião de um } \\
\text { acidente, estes compostos podem ser derramados no solo, podendo alcançar as águas } \\
\text { subterrâneas. }\end{array}$ \\
\hline $\begin{array}{l}\text { Infraestrutura Agrícola (Silos, } \\
\text { Estufas, Granjas, entre outras) }\end{array}$ & 0,70 & $\begin{array}{l}\text { Além do armazenamento de substâncias com potencial de contaminação, há também a } \\
\text { produção de efluentes e resíduos. }\end{array}$ \\
\hline $\begin{array}{l}\text { Infraestrutura de Áreas Comerciais } \\
\text { (Shoppings, Galpões Comerciais, } \\
\text { etc.) e Áreas Institucionais }\end{array}$ & 0,65 & $\begin{array}{l}\text { Apresenta características ocupacionais e de geração de resíduos e efluentes } \\
\text { semelhantes a áreas urbanizadas, porém, em menores volumes. }\end{array}$ \\
\hline Áreas de Lazer e Desporto & 0,60 & $\begin{array}{l}\text { Geralmente estão inseridas na área urbana e, por isso, produzem efluentes e resíduos } \\
\text { com características urbanas. No entanto, a ocupação destes espaços pode ser esporádica } \\
\text { e os impactos ambientais nestes locais podem ser reduzidos. }\end{array}$ \\
\hline Loteamentos & 0,55 & $\begin{array}{l}\text { Integram o tecido urbano, não apresentando edificações tampouco produção de carga } \\
\text { contaminante significativa. Contudo, deve ser considerado o potencial futuro para gerar } \\
\text { contaminação. }\end{array}$ \\
\hline $\begin{array}{l}\text { Espaços Verdes Urbanos (Praças, } \\
\text { Parques, Canteiros Centrais de Vias } \\
\text { Públicas e Faixas de Servidão) }\end{array}$ & 0,45 & $\begin{array}{l}\text { Nos espaços verdes urbanos, a geração de efluentes e resíduos domiciliares e a } \\
\text { utilização de agrotóxicos são pouco significativas. }\end{array}$ \\
\hline \multicolumn{3}{|c|}{ ÁREAS AGROSSILVOPASTORIS } \\
\hline Uso e Cobertura & Índice & Justificativas \\
\hline $\begin{array}{l}\text { Culturas Temporárias (Arroz, } \\
\text { Feijão, Soja, Trigo, Alho, Batata, } \\
\text { Cebola, entre outras) }\end{array}$ & 0,85 & $\begin{array}{l}\text { Além de comprometer a qualidade da recarga (aplicação de agrotóxicos), os cultivos } \\
\text { irrigados elevam as taxas totais de infiltração (recarga artificial), disponibilizando } \\
\text { constantemente mais água para o transporte de poluentes para o aquífero. }\end{array}$ \\
\hline $\begin{array}{l}\text { Culturas Semiperenes } \\
\text { (Cana-de-Açúcar) }\end{array}$ & 0,75 & $\begin{array}{l}\text { Em extensas áreas de monocultura, há intensa utilização de agroquímicos e a lixiviação } \\
\text { destas substâncias para o aquífero pode ser alta, caso a cultura seja desenvolvida em } \\
\text { locais de clima úmido, com solos delgados e bem drenados. }\end{array}$ \\
\hline $\begin{array}{l}\text { Culturas Perenes (Cítricos, Café, } \\
\text { Seringueira, Cacau, Uva, Algodão, } \\
\text { etc.) }\end{array}$ & 0,60 & $\begin{array}{l}\text { Nos cultivos perenes, menores quantidades de nutrientes e agrotóxicos contidos no solo } \\
\text { são transferidas aos aquíferos por lixiviação, quando comparados à agricultura sazonal, } \\
\text { pois há menos perturbação e aeração do solo e a plantação possui necessidades mais } \\
\text { contínuas de nutrientes. }\end{array}$ \\
\hline $\begin{array}{l}\text { Silvicultura (Reflorestamentos e } \\
\text { Cultivos Agroflorestais) }\end{array}$ & 0,50 & $\begin{array}{l}\text { Em linhas gerais, áreas de reflorestamentos e sistemas agroflorestais podem utilizar } \\
\text { quantidades menores de agrotóxicos, quando comparados aos cultivos tradicionais e, } \\
\text { por isso, geram carga contaminante reduzida. }\end{array}$ \\
\hline Pastagens & 0,40 & $\begin{array}{l}\text { O armazenamento e consumo de fertilizantes para o plantio de pastagens também podem levar } \\
\text { à contaminação das águas subterrâneas, especialmente onde tais compostos forem armazenados } \\
\text { de forma inadequada e aplicados em demasia. }\end{array}$ \\
\hline
\end{tabular}

Figura 3 - Proposta de classificação do uso e cobertura do solo em função do potencial de contaminação Fonte: Adaptado de Foster et al. (2006), Gomes (2008), Ribeiro et al. (2001), Albuquerque Filho et al. (2011), Iritani et al. (2013) e COST 620 (2003). 


\begin{tabular}{|c|c|c|}
\hline \multicolumn{3}{|c|}{ ESPAÇOS ABERTOS COM POUCA OU NENHUMA COBERTURA VEGETAL } \\
\hline Uso e Cobertura & Índice & \multicolumn{1}{|c|}{ Justificativas } \\
\hline $\begin{array}{c}\text { Solo Exposto para o Plantio } \\
\text { Agrícola }\end{array}$ & 0,50 & $\begin{array}{l}\text { Ainda que diminuta, uma parcela dos agroquímicos aplicados em cultivos anteriores } \\
\text { fica retida no solo, podendo ser carreada para as águas subterrâneas pelas chuvas. }\end{array}$ \\
\hline \multicolumn{3}{|c|}{ SUPERFÍCIES NATURAIS } \\
\hline $\begin{array}{c}\text { Elorestas, Matas Ciliares, Campos } \\
\text { Naturais e Áreas Úmidas }\end{array}$ & 0,00 & $\begin{array}{l}\text { Em superfícies naturais, não são desenvolvidas atividades com potencial para } \\
\text { contaminar os aquíferos. }\end{array}$ \\
\hline \multicolumn{2}{|c|}{ CORPOS DE ÁGUA } \\
\hline Uso e Cobertura & Índice & \multicolumn{1}{|c|}{ Justificativas } \\
\hline $\begin{array}{c}\text { Cursos D'água, Lagos, Lagoas e } \\
\text { Represas }\end{array}$ & 0,00 & $\begin{array}{l}\text { Assume-se que, em massas d'água e/ou cursos d'água não poluídos, é impossível } \\
\text { ocorrer atividades potencialmente poluidoras. }\end{array}$ \\
\hline
\end{tabular}

Figura 3 (Continuação) - Proposta de classificação do uso e cobertura do solo em função do potencial de contaminação Fonte: Adaptado de Foster et al. (2006), Gomes (2008), Ribeiro et al. (2001), Albuquerque Filho et al. (2011), Iritani et al. (2013) e COST 620 (2003).

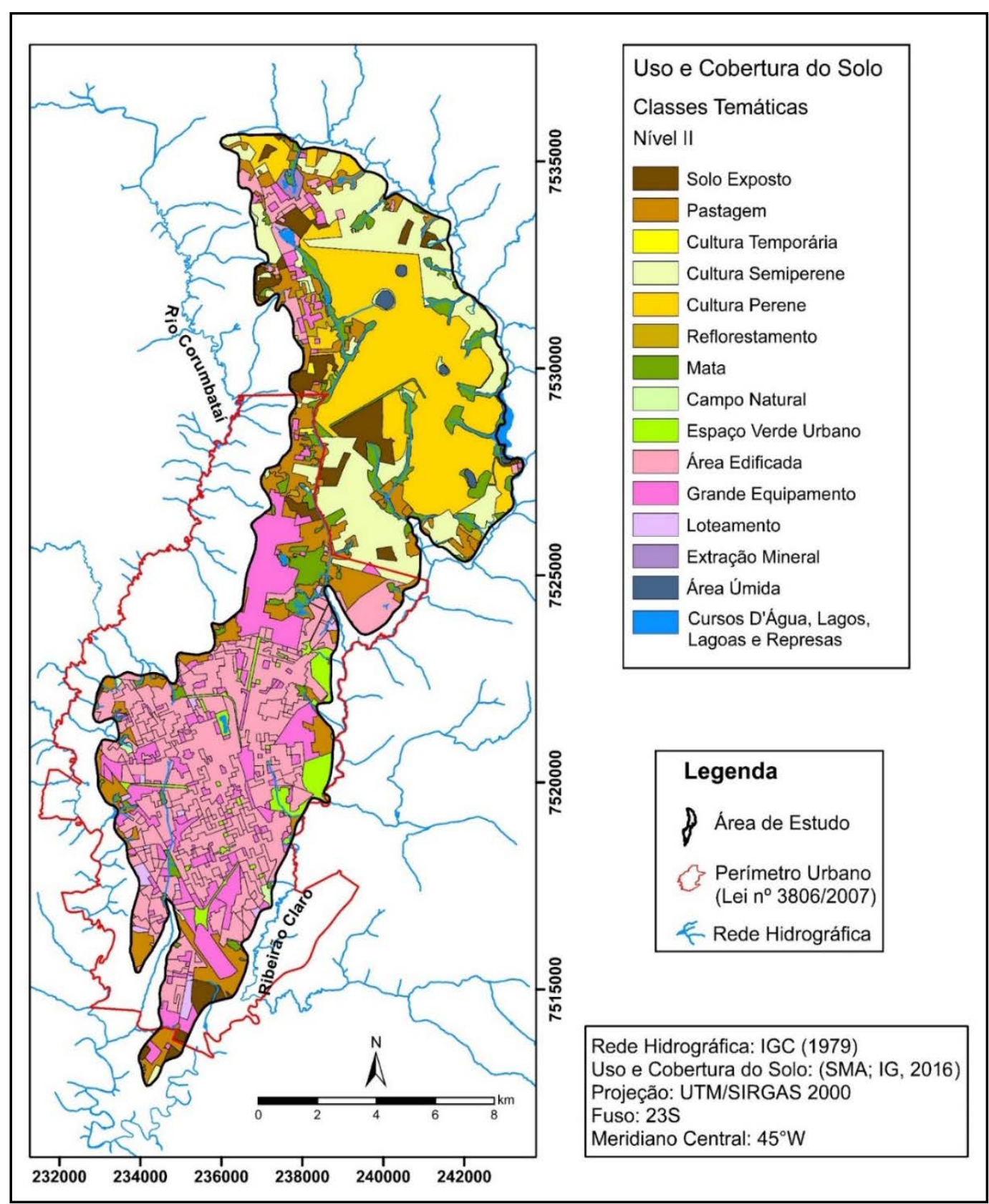

Figura 4 - Mapa de uso e cobertura do solo da área de estudo (Fonte: Adaptado de SMA \& IG, 2016).

São Paulo, UNESP, Geociências, v. 39, n. 4, p. 1069 - 1086, 2020 
Tabela 1 - Escala fundamental de Saaty.

\begin{tabular}{c|c|l}
\hline $\begin{array}{c}\text { Expressão } \\
\text { Numérica }\end{array}$ & $\begin{array}{c}\text { Importância } \\
\text { Comparativa }\end{array}$ & \multicolumn{1}{c}{ Justificativa } \\
\hline 1 & Igualmente & Os dois critérios contribuem igualmente para o objetivo. \\
\hline 3 & Moderadamente & Importância moderada de um critério em relação ao outro. \\
\hline 5 & Fortemente & $\begin{array}{l}\text { Um critério é fortemente mais importante do que outro, } \\
\text { considerando o objetivo do trabalho. }\end{array}$ \\
\hline 7 & Muito Fortemente & Um critério é favorecido muito fortemente sobre o outro. \\
\hline 9 & Extremamente & $\begin{array}{l}\text { A importância de um critério sobre outro é da mais alta } \\
\text { ordem. }\end{array}$ \\
\hline $2,4,6$ e 8 & $\begin{array}{l}\text { Valores intermediários entre escalas } \\
\text { de valor adjacentes. }\end{array}$ & \multicolumn{2}{c}{} \\
\hline
\end{tabular}

Fonte: Adaptado de Saaty (2008).

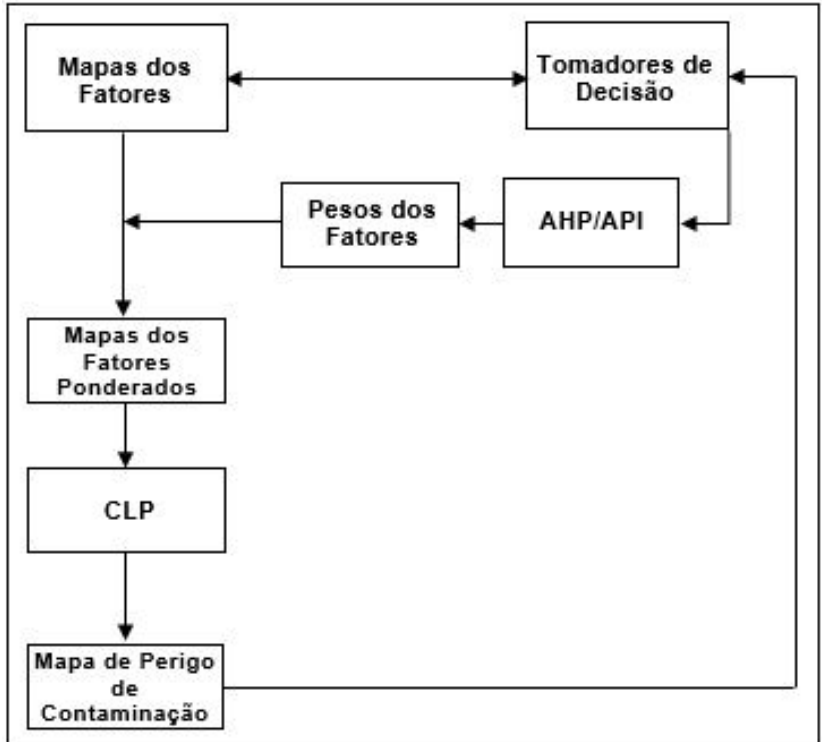

Figura 5 - Processo decisório na estimativa do perigo de contaminação.

\section{RESULTADOS E DISCUSSÃO}

\section{Pesos de importância relativa dos fatores}

A partir da aplicação da AHP e agregação das opiniões dos especialistas através da API, foram obtidos os pesos dos fatores apresentados na tabela 2 .

Tabela 2 - Pesos de importância relativa dos fatores para o perigo de contaminação

\begin{tabular}{c|c|c|c}
\hline Especialista & $\begin{array}{c}\text { Vulnerabilidade } \\
\text { Natural }\end{array}$ & $\begin{array}{c}\text { Uso e Cobertura } \\
\text { do Solo }\end{array}$ & $\begin{array}{c}\text { Razão de } \\
\text { Consistência (RC) }\end{array}$ \\
\hline $\mathbf{1}$ & 0,50 & 0,50 & 0,50 \\
\hline $\mathbf{2}$ & 0,50 & 0,50 & 0,50 \\
\hline $\mathbf{3}$ & 0,40 & 0,60 & 0,40 \\
\hline $\mathbf{4}$ & 0,50 & 0,50 & 0,50 \\
\hline $\mathbf{5}$ & 0,45 & 0,55 & 0,45 \\
\hline $\mathbf{6}$ & 0,50 & 0,50 & 0,50 \\
\hline $\mathbf{7}$ & 0,40 & 0,60 & 0,40 \\
\hline Pesos de Fator & 0,46 & 0,54 & 0,46 \\
\hline
\end{tabular}

Em todos os julgamentos paritários, a Razão de Consistência (RC) foi igual a 0. Neste caso, quando se trata da aplicação da AHP para apenas dois fatores $\mathrm{A}$ e B, a inconsistência da análise não será expressa pela $\mathrm{RC}$, mas sim pela experiência do decisor em estabelecer com precisão as relações entre os fatores e, principalmente, suas contribuições para a ocorrência do fenômeno alvo da tomada de decisão.

Por exemplo, um analista pode considerar que o fator A é mais importante do que $\mathrm{B}$, e vice-versa.

Nestas duas situações hipotéticas, a RC dos 
julgamentos será igual a 0 , cabendo ao especialista atribuir adequadamente as influências relativas aos fatores.

No que refere à AHP, quatro especialistas julgaram os fatores vulnerabilidade natural e o uso e cobertura do solo igualmente importantes, considerando que o perigo de contaminação de um aquífero está estreitamente relacionado à interação, na mesma proporção, entre estes dois fatores.

Entretanto, no entendimento de dois especialistas, as fontes de contaminação representadas pelo uso e cobertura do solo são moderadamente mais importantes do que as características intrínsecas do aquífero expressas pela vulnerabilidade natural. Por fim, apenas um especialista posicionou a influência relativa do fator uso e cobertura do solo entre igualmente e moderadamente mais importante do que a vulnerabilidade na estimativa do perigo.

Na literatura pertinente, não existe uma fronteira bem definida sobre as influências relativas da carga poluente e da vulnerabilidade natural.

Assim como nos principais modelos de avaliação de vulnerabilidade, a ponderação e integração destes fatores para a estimativa do perigo é ainda muito subjetiva, variando de um método para o outro.

A grande dificuldade para estabelecer pesos definitivos para a fonte de contaminação e a vulnerabilidade é que os limites da interação entre eles oscilam de um local ao outro, dependendo muito das características intrínsecas da área e do contaminante ou do grupo de contaminantes envolvidos.

Conforme a média geométrica dos julgamentos, o fator de maior peso foi o uso e cobertura do solo $(0,54)$, seguido da vulnerabilidade natural $(0,46)$.

Esta ponderação entre os critérios tem influência direta sobre a distribuição espacial das áreas de perigo a serem geradas pela estimativa. Neste caso, espera-se que produto apresente áreas de maior perigo de contaminação situadas principalmente em locais com vulnerabilidade natural elevada, onde se desenvolvem atividades potencialmente poluidoras, e vice-versa.

Em síntese, os índices de perigo de contaminação podem ser obtidos a partir da Equação 3:

$$
\mathrm{P}=0,46 . \mathrm{VN}+0,54 . \mathrm{US}
$$

onde: $\mathrm{P}=$ mapa de perigo de contaminação; $\mathrm{VN}$ = mapa normalizado de vulnerabilidade natural; US = mapa de uso e ocupação do solo, classificado conforme o potencial de contaminação das fontes.

\section{Mapa de perigo de contaminação do Aquífero Rio Claro}

$\mathrm{Na}$ figura 6 são apresentados os mapas normalizados dos fatores vulnerabilidade natural e uso e cobertura do solo. A figura 7 mostra o mapa de perigo de contaminação do aquífero Rio Claro, em escala contínua de valores e também segundo a classificação proposta.

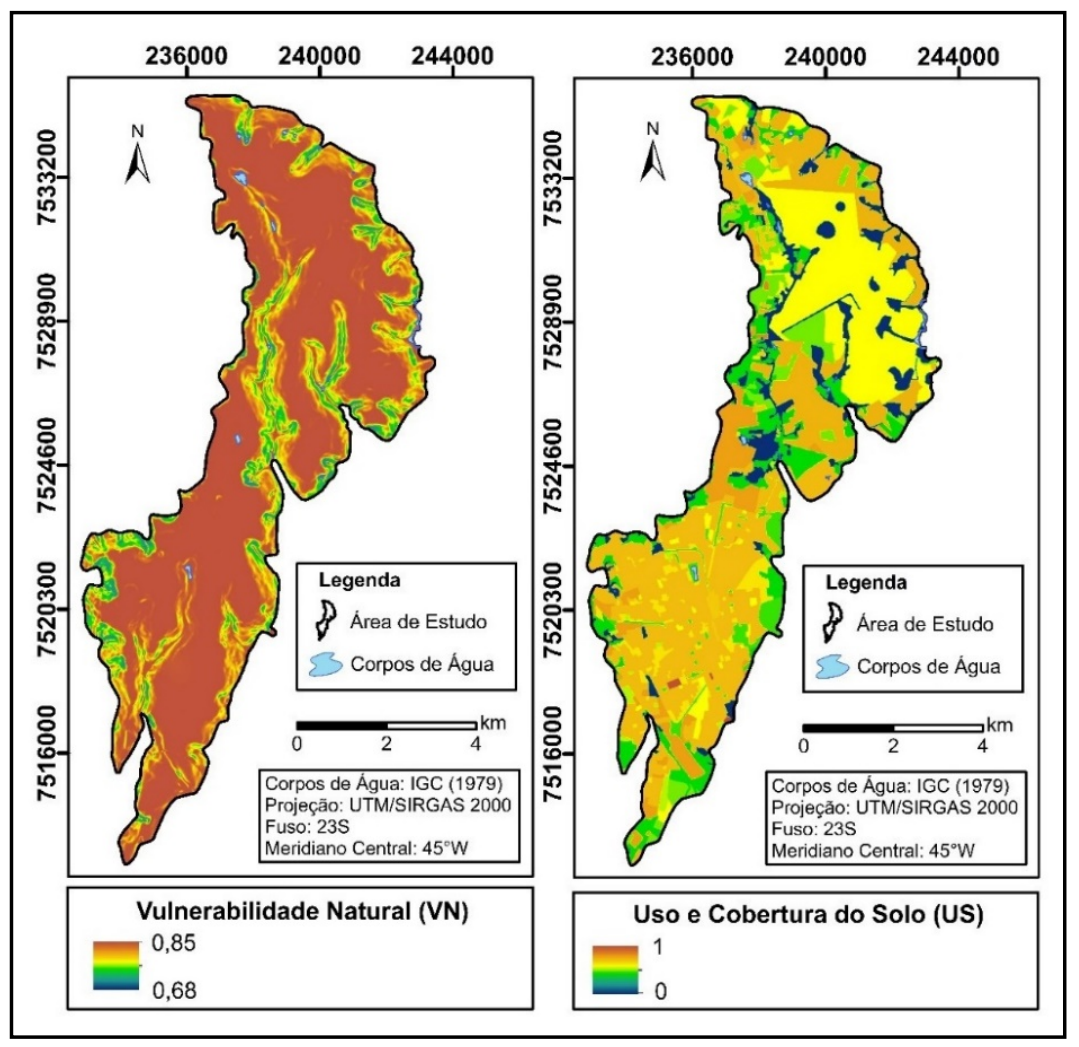

Figura 6 - Mapas normalizados dos fatores. 


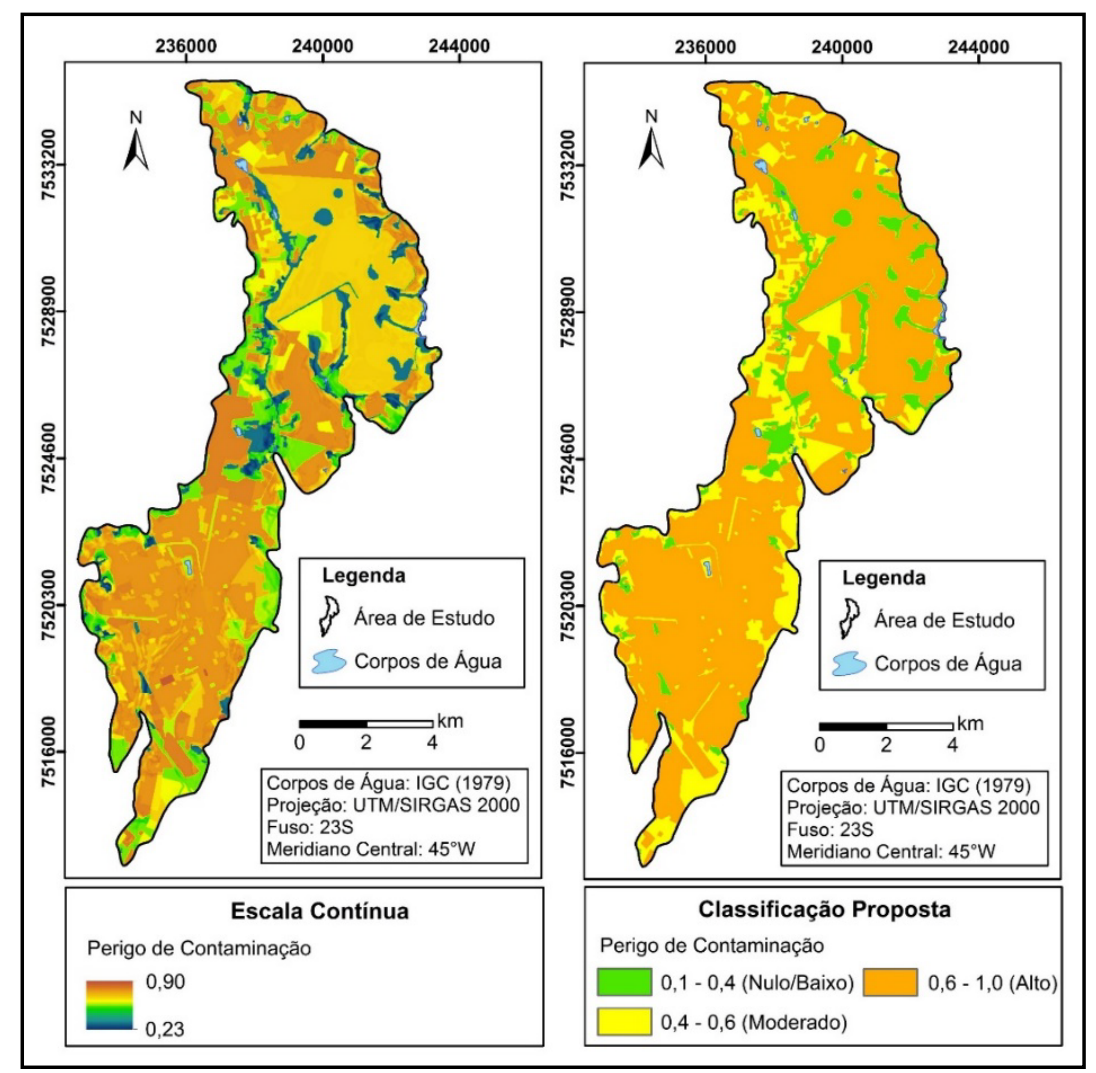

Figura 7 - Mapa de perigo de contaminação do Aquífero Rio Claro.

Em grande parte da área de estudo predominam e de cítricos, que juntos representam 65\% da área classes de uso e cobertura do solo com índices de potencial de contaminação significativos, como a área urbano-industrial, cultivos de cana-de-açúcar total (Figura 8). Como resultado disto e da elevada vulnerabilidade natural, $72 \%$ da área de estudo apresentaram alto perigo de contaminação.

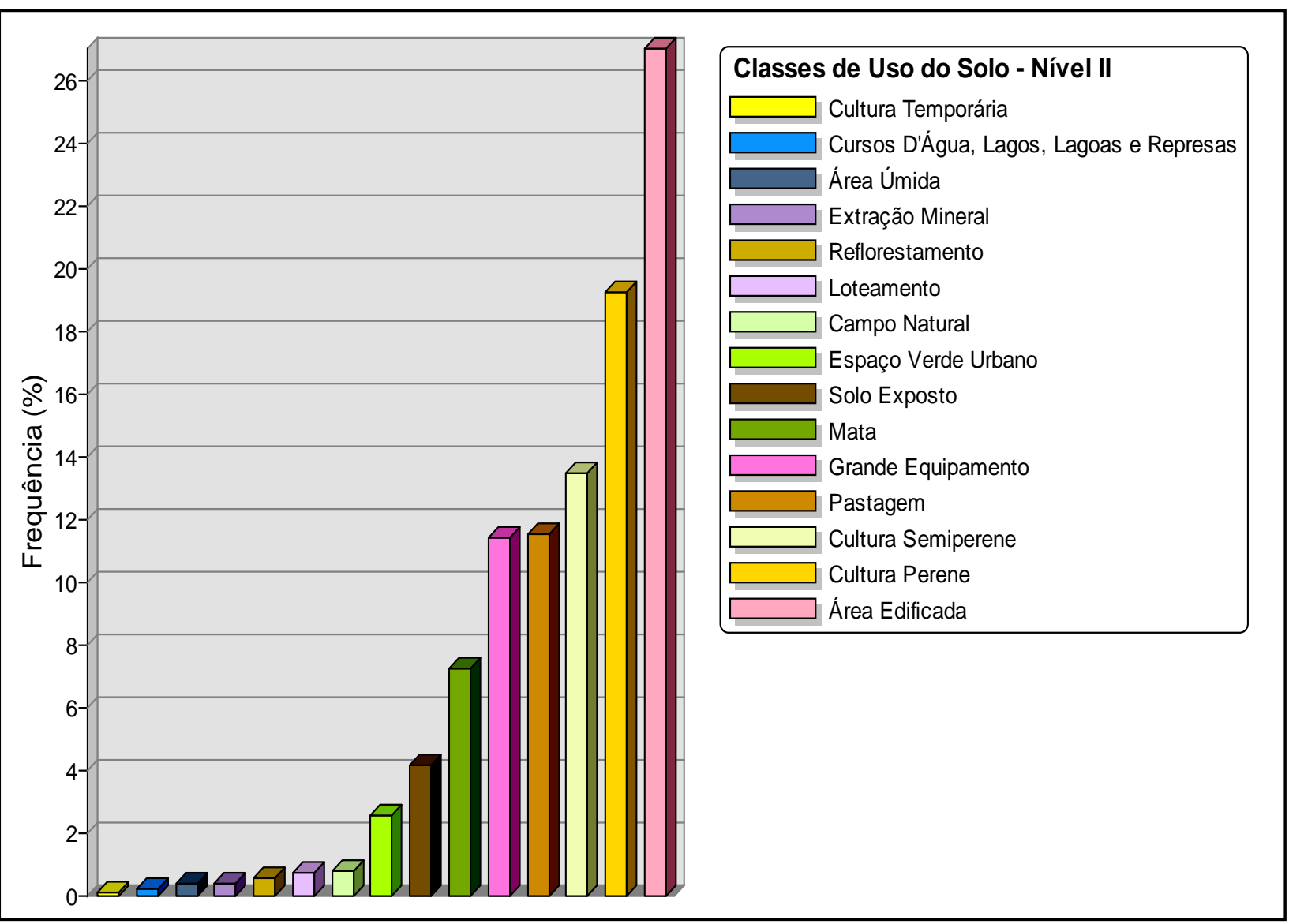

Figura 8 - Frequência relativa das classes de uso e cobertura do solo - nível II de abstração. 
Em segundo plano, foram identificadas áreas com perigo de contaminação moderado, que representam 19\% da área de estudo, restringindose às regiões de solos expostos para o plantio agrícola e de pastos limpos.

As áreas com perigo de contaminação nulo ou baixo correspondem a aproximadamente $9 \%$ do aquífero Rio Claro, concentrando-se em locais de ocorrência de fontes com potencial de contaminação desprezível, como é o caso das áreas úmidas, campo natural e mata, na qual se situa cerca de $84 \%$ das áreas com perigo de contaminação nulo/baixo.
Portanto, é oportuno reafirmar a importância da preservação de remanescentes florestais, pois contribuem para a garantia da quantidade e manutenção da qualidade dos recursos hídricos superficiais e subterrâneos.

Na figura 9 é apresentada a frequência relativa das classes de perigo de contaminação. $\mathrm{Na}$ Tabela 3 é apresentada uma tabulação cruzada entre as classes de perigo e de uso e cobertura do solo (nível III de abstração).

A figura 10 ilustra alguns exemplos da distribuição do perigo entre as classes de uso e cobertura do solo, considerando também o nível III de abstração.

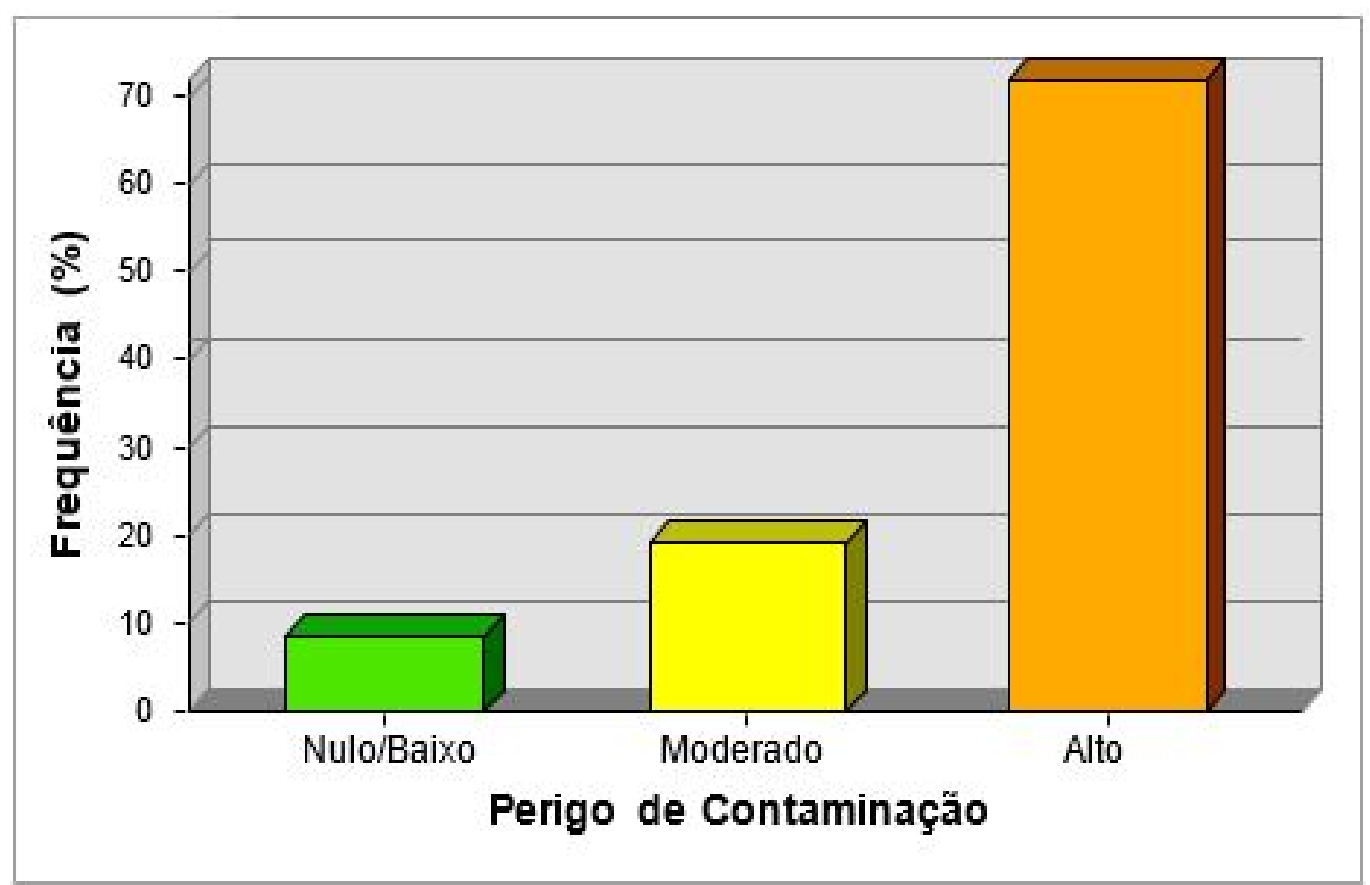

Figura 9 - Frequência relativa das classes de perigo de contaminação do aquífero Rio Claro.

Tabela 3 - Tabulação cruzada entre as classes de perigo de contaminação e de uso e cobertura do solo (nível III de abstração).

\begin{tabular}{|c|c|c|}
\hline $\begin{array}{c}\text { Perigo de } \\
\text { Contaminação }\end{array}$ & $\begin{array}{l}\text { Classe de Uso e } \\
\text { Cobertura do Solo }\end{array}$ & $\begin{array}{c}\text { Frequência } \\
\text { Relativa (\%) }\end{array}$ \\
\hline \multirow{5}{*}{ Alto } & Cítricos & 24,55 \\
\hline & Cana-de-Açúcar & 18,74 \\
\hline & $\begin{array}{c}\text { Edificações Horizontais, } \\
\text { Densidade de Ocupação Alta, } \\
\text { Estágio de Ocupação Consolidado e Ordenamento Urbano Muito Alto }\end{array}$ & 15,84 \\
\hline & $\begin{array}{l}\text { Edificações Horizontais, } \\
\text { Densidade de Ocupação Alta, } \\
\text { Estágio de Ocupação Consolidado e Ordenamento Urbano Alto }\end{array}$ & 9,40 \\
\hline & Indústria & 8,60 \\
\hline \multirow{2}{*}{ Moderado } & Pasto Limpo & 53,24 \\
\hline & Solo Exposto para Plantio Agrícola & 21,53 \\
\hline \multirow{3}{*}{ Nulo/Baixo } & Mata & 83,79 \\
\hline & Campo Natural & 9,09 \\
\hline & Área Úmida & 4,75 \\
\hline
\end{tabular}




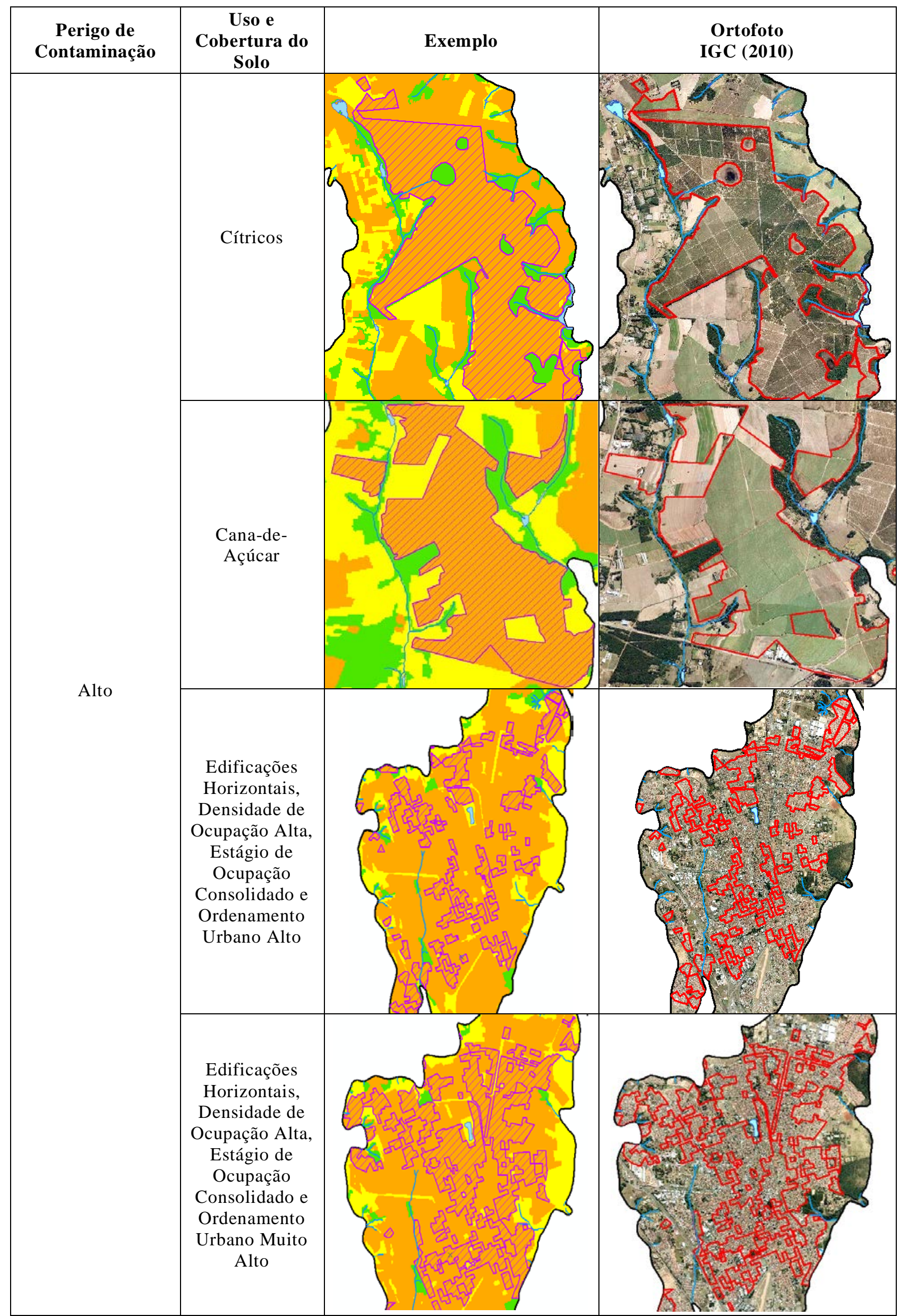

Figura 10 - Exemplos da distribuição do perigo entre as classes de uso e cobertura do solo, nível III de abstração. 


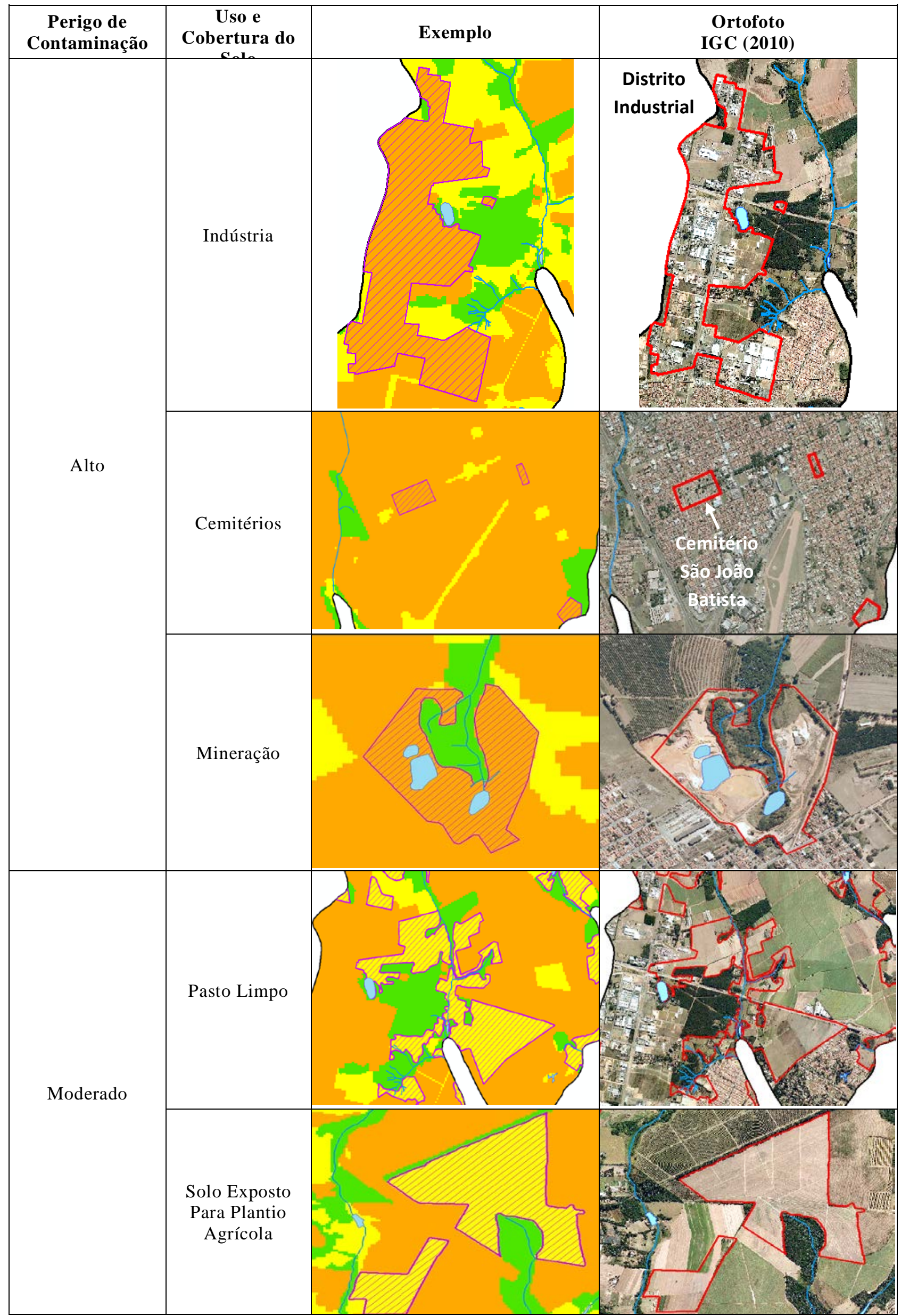

Figura 10 - (Continuação) - Exemplos da distribuição do perigo entre as classes de uso e cobertura do solo, nível III de abstração.

São Paulo, UNESP, Geociências, v. 39, n. 4, p. 1069 - 1086, 2020 


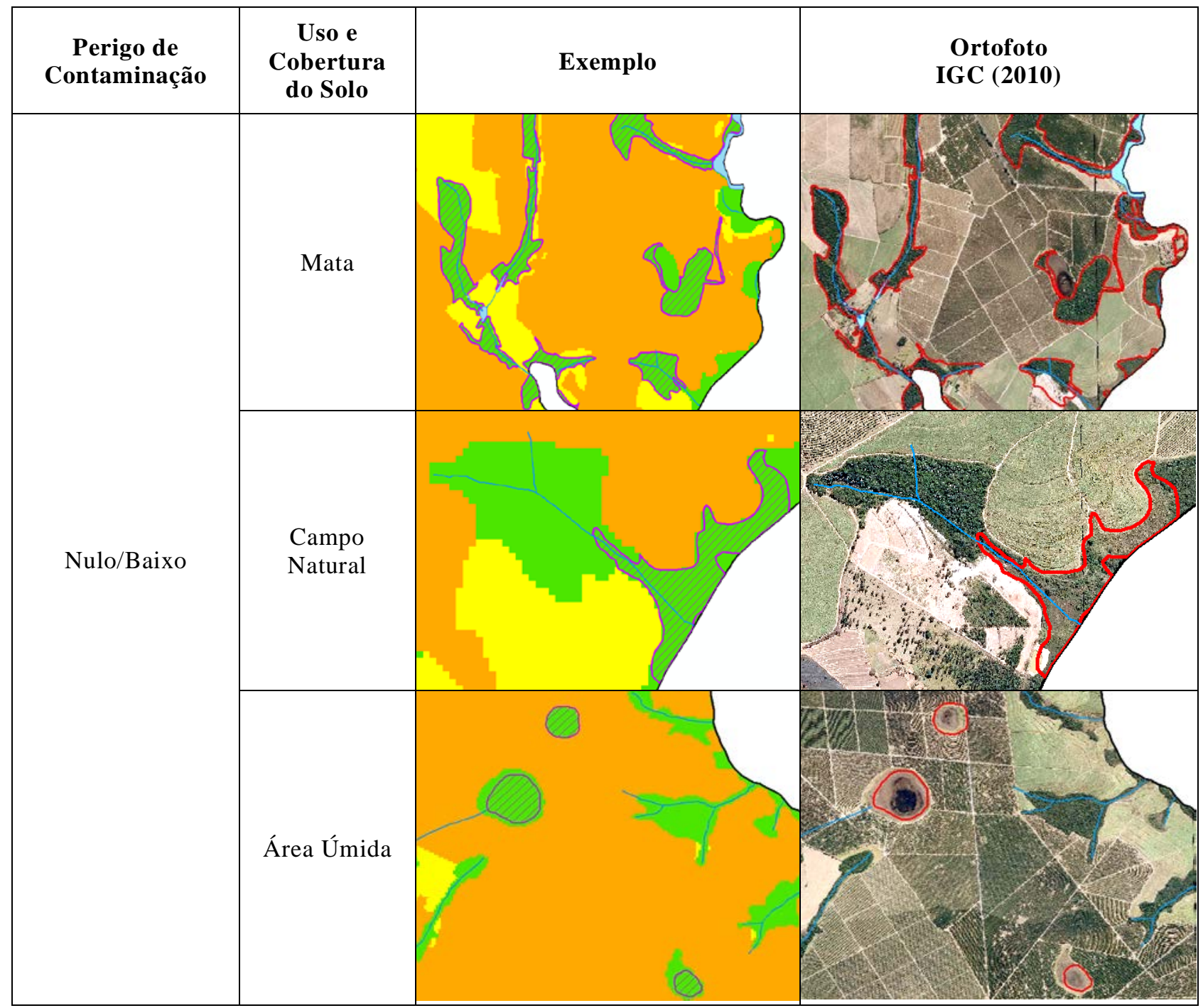

Figura 10 - (Continuação) - Exemplos da distribuição do perigo entre as classes de uso e cobertura do solo, nível III de abstração.

Com base na análise da distribuição do perigo de contaminação entre as classes de uso e cobertura do solo (Tabela 3), as áreas com alto perigo concentram-se principalmente em locais de cultivo de cítricos e de cana-de-açúcar, representando $43 \%$ do total.Nos últimos anos, houve uma grande expansão do setor sucroalcooleiro na região centro-sul do Brasil, em detrimento de outras culturas como laranja e café (IBGE, 2015). No município de Rio Claro/SP, os canaviais ocupam cerca de $30 \%$ da superfície total (INPE, 2019). Deste percentual, metade está inserida na área de estudo (SMA \& IG, 2016). Segundo o zoneamento agroambiental para a cana-de-açúcar no Estado de São Paulo, a área de estudo apresenta aptidão edafoclimática favorável a este tipo de cultivo. Porém, existem algumas restrições ambientais, destacando-se, dentre elas, a alta vulnerabilidade natural à contaminação das águas subterrâneas (SMA \& SAA, 2008). Portanto, os possíveis impactos na qualidade do aquífero Rio Claro devem ser avaliados e monitorados, devido à intensa utilização de defensivos agrícolas e de fertilizantes nitrogenados em áreas naturalmente muito vulneráveis à contaminação.

Nesse sentido, é crescente a preocupação com a fertirrigação dos canaviais por vinhaça, que é um efluente da fabricação do etanol, a partir da destilação fracionada do caldo fermentado da cana-de-açúcar. Caso seja aplicada corretamente, a vinhaça proporciona várias melhorias nas condições do solo, tais como: o aumento da fertilidade (contém significativas concentrações de nitrogênio, fósforo e potássio), do teor de matéria orgânica e da disponibilidade de água. Entretanto, face à dimensão do problema da aplicação excessiva deste efluente e da ausência de controle sobre a disposição nos solos, a vinhaça tem se tornado uma ameaça constante à qualidade das águas subterrâneas.

Por isso, a CETESB (2006) estabeleceu, por meio da norma P4.231/06, os critérios e procedimentos para o armazenamento, transporte 
e aplicação da vinhaça nos solos do Estado de São Paulo. Segundo esta norma, para que a fertirrigação transcorra de modo seguro e eficaz, é necessária a caraterização tanto do solo quanto da vinhaça, possibilitando o cálculo da dosagem máxima permitida. Por estas razões, deve haver cautela na aplicação da vinhaça como biofertilizante em áreas de recarga de aquíferos livres, como é o caso das regiões canavieiras assentadas sobre o aquífero Rio Claro.

No contexto urbano, as edificações horizontais, com densidade de ocupação alta, estágio de ocupação consolidado e ordenamento urbano entre alto e muito alto correspondem a $25 \%$ das áreas com alto perigo de contaminação. Na prática, esta porção do tecido urbano abriga uma vasta gama de atividades potencialmente poluidoras, sobretudo os postos de combustíveis, que representam $71 \%$ das áreas declaradamente contaminadas, tanto no Estado de São Paulo como no município de Rio Claro/SP (CETESB, 2019).

Além disso, devem ser consideradas as questões relativas ao saneamento básico municipal, tais como: a coleta, o transporte e o tratamento de esgotos domésticos, incluindo a manutenção/troca de redes coletoras obsoletas e o gerenciamento de resíduos sólidos em áreas urbanas muito consolidadas (Francisco, 2018).

As indústrias representam cerca de $9 \%$ das áreas com alto de perigo de contaminação e, segundo a CETESB (2019), das 31 áreas declaradas como contaminadas no município de Rio Claro, apenas 5 são referentes a atividades industriais, que se relacionam principalmente ao setor químico (fabricação de resinas e de fibras de vidro).

Entretanto, acredita-se que este número deva ser bem maior, tendendo a aumentar devido a ações rotineiras de fiscalização e de licenciamento ambiental. Portanto, é imprescindível que o controle e o monitoramento ambiental sejam intensificados, sobretudo, no Distrito Industrial do município.

Os cemitérios representam apenas $0,2 \%$ das áreas com alto perigo de contaminação. Nos últimos anos, a maior preocupação quanto aos cemitérios é a possibilidade de contaminação dos aquíferos pelo necrochorume, configurando um problema ambiental e de saúde pública. A respeito disto, a Resolução SMA n ${ }^{\circ}$ 10/2017 definiu os serviços de sepultamento como sendo uma atividade potencialmente geradora de áreas contaminadas (São Paulo, 2017)

Tal como ocorre na maior parte do Brasil, no município de Rio Claro os cemitérios estão totalmente integrados à área urbana, devido à ausência de planejamento ambiental pretérito desta atividade, que por sua vez, está profundamente atrelado a questões históricoculturais e religiosas. Por isso, surgiu a necessidade de regulamentação dos aspectos essenciais relativos ao processo de licenciamento ambiental de cemitérios, materializados na Resolução CONAMA nº 335/03 (Brasil, 2003).

No cemitério municipal São João Batista, situado na área urbana do município de Rio Claro, não existem medidas mitigadoras e de monitoramento ambiental, com vistas à proteção das águas subterrâneas. Em um estudo sobre métodos geoelétricos aplicados ao diagnóstico ambiental e subsuperficial desta área, Xavier et al. (2018) relacionou os baixos valores de resistividade elétrica a locais possivelmente contaminados por necrochorume, sobretudo em regiões de ocupação mais antiga, datadas da construção do cemitério, no século XIX. Portanto, é necessário que o monitoramento nesta área seja constante, pois além de oferecer alto perigo de contaminação às águas subterrâneas exploradas em poços circunvizinhos, há indícios de que já constitua uma área contaminada.

Quanto às regiões de extração mineral, estas foram classificadas com alto perigo de contaminação. Na área estudo, a atividade minerária é caracterizada pela exploração de areia em cava, cujo principal mercado consumidor são os setores industrial e construção civil. A mineração de areia apresenta menor potencial gerador de cargas contaminantes em comparação com a exploração de metais, carvão e petróleo, pois se trata de um bem mineral não metálico, quase sempre constituído por substâncias não perigosas e inertes.

Todavia, deve ser considerada a carga poluente gerada por eventuais vazamentos de óleos, graxas e combustíveis do maquinário utilizado para a escavação, desmonte e lavagem do minério, inclusive os materiais empregados para a recuperação ambiental da área. Conforme Mechi \& Sanches (2010), grandes cavas de extração de areia por desmonte hidráulico, próximas a centros urbanos, têm sido aterradas com resíduos inertes provenientes de entulho da construção civil, cuja adequação vem sendo contestada em face da ausência de controle da 
qualidade desses resíduos, que podem conter substâncias não inertes e, eventualmente, perigosas, podendo contaminar as águas subterrâneas e colocar em risco a saúde humana.

Além destes fatores, este tipo de mineração pode tornar o aquífero ainda mais vulnerável à contaminação, uma vez que há a remoção da zona não saturada, quase sempre expondo a superfície freática e diminuindo a capacidade de degradação dos contaminantes ao longo do perfil geológico. No caso da área de estudo, o monitoramento dos processos de extração e beneficiamento da areia deve ser ainda maior, visto que estas atividades se desenvolvem em porções altamente vulneráveis da Formação Rio Claro.

\section{CONSIDERAÇÕES FINAIS}

A alta vulnerabilidade do aquífero Rio Claro impõe muitas restrições quanto ao uso e ocupação do solo. Por isso, o exercício de atividades com significativo potencial poluidor deve ser planejado e gerenciado com muita cautela pelos gestores públicos municipais.

Em relação a isso, o enfoque deve ser o monitoramento ambiental de práticas agrícolas, indústrias e de postos de combustíveis, que por sua vez, constituem a maior parte das áreas declaradas contaminadas no município. Além disso, atividades econômicas com impacto local devem ser acompanhadas pelos órgãos ambientais de controle, mesmo que sejam de menor porte, como por exemplo, oficinas mecânicas, ferros-velhos e lava-rápidos.

Embora comparações não possam ser estabelecidas, pois não existem contribuições anteriores no que se refere à estimativa do perigo de contaminação do aquífero Rio Claro empregando outros modelos de avaliação, o produto gerado apresentou resultados consistentes, considerando a alta vulnerabilidade natural e o potencial de contaminação das fontes existentes na área de estudo.

É importante destacar que os índices provenientes do modelo de avaliação proposto poderão ser investigados com mais detalhe em cada local, sobretudo naqueles onde o perigo é alto (áreas urbano-industriais e minerações), a partir de uma avaliação minuciosa que poderá redefinir as categorias de perigo, com o propósito de identificar áreas prioritárias. Devido ao caráter regional da escala de mapeamento das fontes de contaminação, o mapa gerado exibe um quadro geral, que forçosamente implica na utilização deste produto como reconhecimento preliminar da distribuição espacial do perigo. Logo, o nível de detalhamento oferecido pelo método proposto estará atrelado à escala de apresentação dos dados de entrada, sobretudo das fontes de contaminação.

Ainda que uma determinada área apresente perigo de contaminação elevado, este também depende das ações de gerenciamento e controle das cargas poluidoras geradas em cada atividade ou empreendimento. A título de exemplo, áreas industriais que, a princípio, foram classificadas com alto perigo de contaminação, podem ter seus índices reduzidos, caso sejam adotadas medidas para prevenir a contaminação das águas subterrâneas.

A propósito, recomenda-se a integração dos índices atribuídos às fontes de contaminação a fatores de redução, cuja finalidade será refletir as condições físicas e operacionais de cada empreendimento, ou seja, as medidas de manutenção e segurança que possam repercutir na proteção do aquífero Rio Claro contra a poluição.

\section{AGRADECIMENTOS}

Os autores gostariam de agradecer ao Departamento de Geologia Aplicada, do Instituto de Geociências e Ciências Exatas - IGCE/UNESP pelo suporte técnico e à Coordenação de Aperfeiçoamento de Pessoal de Nível Superior - CAPES, pelo auxílio financeiro na forma de concessão de bolsa de estudo.

\section{REFERÊNCIAS}

ABRELPE - ASSOCIAÇÃO BRASILEIRA DE EMPRESAS DE LIMPEZA PÚBLICA E RESÍDUOS ESPECIAIS. Panorama dos resíduos sólidos no Brasil 2018/2019. São Paulo: ABRELPE, 2019. Disp. em: <https://www.migalhas .com.br/arquivos/2020/1/492DD855EA0272_PanoramaAbrelp e_-2018_2019.pdf $>$. Acesso em: 17 jul. 2020.

ALBUQUERQUE FILHO, J.L.; BARBOSA, M. C.; DE
CARVALHO, A.M.; IKEMATSU, P.; CAVANI, A.C.M. Avaliação do perigo de contaminação do Sistema Aquífero Guarani em sua área de afloramento do Estado de São Paulo decorrente das atividades agrícolas. Águas Subterrâneas, v. 25, n. 1, p. 1-14, 2011.

BRAGA, A.C.O. Geofísica aplicada: métodos geoelétricos em hidrogeologia. 1. ed. São Paulo: Oficina de Textos, 160, p. 2016. 
BRAGA, A.C.O.; FRANCISCO, R.F.; BIRELLI, C.A.; BLANCO, R.G. Aplicação da condutância longitudinal na estimativa da vulnerabilidade natural do Sistema Aquífero Guarani no Estado de São Paulo. Geociências, v. 37, n. 4, p. 807 - 822, 2018.

BRASIL. Ministério do Meio Ambiente. Resolução CONAMA $\mathbf{n}^{0} 335$ de 03 de abril de 2003. Dispõe sobre o licenciamento ambiental de cemitérios. Diário Oficial da União: República Federativa do Brasil, Poder Executivo, Brasília, DF, 03 abr. 2003. Disp. em: <http://www.mma.gov.br/port/conama/legia bre.cfm?codlegi=359>. Acesso em: 02 mar. 2020.

CETESB - COMPANHIA AMBIENTAL DO ESTADO DE SÃO PAULO. Norma técnica P4. 321. Vinhaça - critérios e procedimentos para aplicação no solo agrícola. 2006. Disp. em: < https://cetesb.sp.gov.br/wp-content/uploads/2013/11/ NTC-P4.231_Vinhaça_-Critérios-e-procedimentos-para-aplica ção-no-solo-agrícola-3a-Ed-2a-VERSÃO.pdf>. Acesso em: 13 set. 2019.

CETESB - COMPANHIA AMBIENTAL DO ESTADO DE SÃO PAULO. Texto explicativo: relação de áreas contaminadas e reabilitadas do Estado de São Paulo. 2019. Disp. em: <https://cetesb.sp.gov.br/areas-contaminadas/wpcontent/uploads/sites/17/2020/02/TEXTO-EXPLICATIVO2019-12.02.20.pdf >. Acesso em: 28 jun. 2020.

CHANG, H.K. \& NOGUEIRA, G.E.H. Simulação numérica de fluxo de águas subterrâneas do aquífero Rio Claro, porção nordeste do município de Rio Claro, SP. Águas Subterrâneas, v. 29, n. 2, p. 175-190, 2015.

CHANG, H.K.; CAETANO CHANG, M.R.; OLIVA, A. Determinação da condutividade hidráulica da Formação Rio Claro: análise comparativa através de análise granulométrica e ensaios com permeâmetro Guelph e testes de Slug. Águas Subterrâneas, v. 19, n. 2, p. 1-17, 2005.

ÇIL, A.; MUHAMMETOGLU, A.; OZYURT, N. N.; YENILMEZ, F.; KEYIKOGLU, R.; AMIL, A.; MUHAMMETOGLU, $\mathrm{H}$. Assessment of groundwater contamination risk with scenario analysis of hazard quantification for a karst aquifer in Antalya, Turkey. Environmental Earth Sciences, v. 79, n. 191, 2020.

COST 620 - COOPERATION IN SCIENCE AND TECHNOLOGY (EUROPEAN COMMISSION). ZWAHLEN, F. (Ed.). Vulnerability and risk mapping for the protection of carbonate (karst) aquifers: Final Report. 1. ed. Luxemburgo: European Communities, 2003. 297 p.

DAEE - DEPARTAMENTO DE ÁGUAS E ENERGIA ELÉTRICA. Estudo de águas subterrâneas - região administrativa 5 (Campinas). São Paulo: DAEE, 1981. v. 1 e v. 2.

ENTEZARI, M.; YAMANI, M.; AGHDAM, M. J. Evaluation of intrinsic vulnerability, hazard and risk mapping for karst aquifers, Khorein aquifer, Kermanshah province: a case study. Environmental Earth Sciences, v. 75, n. 5, p. 1-10, 2016.

FORMAN, E. \& PENIWATI, K. Aggregating individual judgements and priorities with the Analytic Hierarchy Process. European Journal of Operational Research, v. 108, p. 165169, 1998.

FOSTER, S. \& HIRATA, R. Avaliação do risco de poluição das águas subterrâneas: uma metodologia baseada em dados existentes. Organização Mundial de Saúde, Organização Panamericana de Saúde, Centro Pan-americano de Engenharia Sanitária e Ciências Ambientais. Lima, 78 p., 1988.

FOSTER, S. S. D.; HIRATA, R.; GOMES, D.; D’ELIA, M.; PARIS, M. Proteção da qualidade da água subterrânea: um guia para empresas de abastecimento de água, órgãos municipais e agências ambientais. Edição brasileira: SERVMAR - Serviços Técnicos Ambientais Ltda., 2006. Banco Mundial. $104 \mathrm{p}$

FRANCISCO, R.F. Contribuição metodológica à estimativa da vulnerabilidade natural e perigo de contaminação de aquíferos livres granulares. Rio Claro, 2018. Tese (Doutorado em Geociências e Meio Ambiente), Instituto de Geociências e
Ciências Exatas, Universidade Estadual Paulista.

FRANCISCO, R.F.; BRAGA, A.C.O.; ALBUQUERQUE FILHO, J. L. SDR: um novo método para avaliar a vulnerabilidade natural à contaminação de aquíferos livres granulares. Geociências, v. 38, n. 1, p. 207 - 219, 2019.

GOMES, M.A.F. (Ed.). Uso agrícola das áreas de afloramento do Aquífero Guarani no Brasil: implicações para a água subterrânea e propostas de gestão com enfoque agroambiental. Brasília: EMBRAPA, 2008. 417 p.

IBGE - INSTITUTO BRASILEIRO DE GEOGRAFIA E ESTATÍSTICA. Levantamento sistemático da produção agrícola: pesquisa mensal de previsão e acompanhamento das safras agrícolas no ano civil. Rio de Janeiro: IBGE, Diretoria de Pesquisas, Coordenação de Agropecuária, 2015. 88 p. v. 29, n.12.

IG - INSTITUTO GEOLÓGICO. Formações geológicas de superfície do Estado de São Paulo. São Paulo: Instituto Geológico, 1986. Articulações: SF-23-M-II-3 (Araras), SF-23M-I-4 (Rio Claro). Escala 1:50.000.

IGC - INSTITUTO GEOGRÁFICO E CARTOGRÁFICO DO ESTADO DE SÃO PAULO. Ortofotos do Estado de São Paulo. São Paulo: Instituto Geográfico e Cartográfico, 2010.

INPE - INSTITUTO NACIONAL DE PESQUISAS ESPACIAIS. Projeto CANASAT: mapa do cultivo de canade-açúcar, 2019. Disp. em: <http://www.dsr.inpe.br/laf/ canasat/cultivo.html>. Acesso em: 03 jul. 2020.

IRITANI, M. A.; ROSSINI-PENTEADO, D.; EZAKI, S.; ODA, G. H. Proposta de classificação das fontes potenciais de contaminação da água subterrânea. Revista do Instituto Geológico do Estado de São Paulo, v. 34, n. 2, p. 1-26, 2013.

JENIFER, M.A. \& JHA, M.K. Comprehensive risk assessment of groundwater contamination in a weathered hard-rock aquifer system of India. Journal of Cleaner Production, v. 201, p. 853-868, 2018.

KAZAKIS, N. \& VOUDOURIS, K.S. Groundwater vulnerability and pollution risk assessment of porous aquifers to nitrate: modifying the DRASTIC method using quantitative parameters. Journal of Hydrology, v. 525, p. 13-25, 2015.

KUMAR, A. \& KRISHNA, A.P. Groundwater vulnerability and contamination risk assessment using GIS-based modified DRASTIC-LU model in hard rock aquifer system in India. Geocarto International, p. 1-30, 2019.

MECHI, A. \& SANCHES, D. L. Impactos ambientais da mineração no Estado de São Paulo. Estudos Avançados, v. 24, n. 68, p. 209-220, 2010.

MEIRA, J.C.R.; DE-CAMPOS, A.B.; PEREIRA, L.C. Vulnerabilidade natural e perigo à contaminação de zona de recarga do Aquífero Guarani. Águas Subterrâneas, v. 28, n. 1, p. 31-46, 2014.

MELO, S.M. A Formação Rio Claro e depósitos associados: sedimentação Neocenozóica na Depressão Periférica Paulista. 1995. 144 p. Tese (Doutorado em Geociências) - Instituto de Geociências, Universidade de São Paulo, São Paulo, 1995.

OLIVA, A. Estudo hidrofaciológio do aquífero Rio Claro no município de Rio Claro - SP. 2006. 244 p. Tese (Doutorado em Geociências e Meio Ambiente) - Instituto de Geociências e Ciências Exatas, Universidade Estadual Paulista, Rio Claro, 2006.

RIBEIRO, L.; FRANCÉS, A.; PARALTA, E.; FERNANDES, J. Development and application in the Alentejo region of a method to assess the vulnerability of groundwater to diffuse agricultural pollution: the susceptibility index. 3. ed. Lisboa: Internacional Conference on Future Groundwater Resources at Risk, 2001.

SAATY, T.L. Decision making with the analytic hierarchy process. International Journal of Services Sciences, v. 1, n. 1, p. 83-98, 2008.

SAATY, T.L. The Analytic Hierarchy Process. New York: McGraw-Hill, 1980. 287 p.

SÃO PAULO. Secretaria de Meio Ambiente do Estado de São Paulo - SMA. Resolução SMA n ${ }^{\circ} 10$ de 08 de fevereiro de 2017. Dispõe sobre a definição das atividades potencialmente 
geradoras de áreas contaminadas. Diário Oficial do Estado: São Paulo, Poder Executivo, São Paulo, SP, 10 fev. 2017. Disp. em: $<$ http://arquivos.ambiente.sp.gov.br/legislacao/2017/02/resolucaosma-010-2017-definicao-das-atividades-potencialmente-

geradoras-de-areas-contaminadas.pdf> . Acesso em: 04 ago. 2019.

SMA - SECRETARIA DE MEIO AMBIENTE DO ESTADO

DE SÃO PAULO \& IG - INSTITUTO GEOLÓGICO. Mapeamento do uso e cobertura do solo da UGRHI 5 (PCJ) - escala 1:25.000. São Paulo, 2016.

SMA - SECRETARIA DE MEIO AMBIENTE DO ESTADO DE SÃO PAULO \& SAA - SECRETARIA DE AGRICULTURA E ABASTECIMENTO DO ESTADO DE SÃO PAULO. Zoneamento agroambiental para o setor sucroalcooleiro no Estado de São Paulo. São Paulo, 2008.

SULLIVAN, T.P. \& GAO, Y. Development of a new P3 (Probability, Protection, and Precipitation) method for vulnerability, hazard, and risk intensity index assessments in karst watersheds. Journal of Hydrology, v. 549, p. 428-451, 2017.

VOOGD, H. Multicriteria evaluation for urban and regional planning. London: Pion, 1983. 370 p.
XAVIER, F.V.; MALAGUTTI FILHO, W.; SILVA, R.W.C.; MOREIRA, C.A. Emprego da sondagem elétrica vertical integrada às análises químicas e microbiológicas no diagnóstico preliminar da contaminação do solo e da água subterrânea no cemitério municipal da cidade de Rio Claro (SP). Engenharia Sanitária e Ambiental, v. 23, p. 1-12, 2018.

ZAINE, J.E. Geologia da Formação Rio Claro na Folha Rio Claro - SP. 1994. 90 p. Dissertação (Mestrado em Geociências) - Instituto de Geociências e Ciências Exatas, Universidade Estadual Paulista, Rio Claro, 1994.
Submetido em 21 de julho de 2020 Aceito para publicação em 17 de outubro de 2020 